\title{
DETERMINATION OF MIXING ZONES FOR WASTEWATER WITH RECEIVER WATERS
}

\author{
Mirosław Skorbiłowicz' ${ }^{1}$ Elżbieta Skorbiłowicz' ${ }^{1}$ Paulina Wójtowicz' ${ }^{1}$ Emilia Zamojska' \\ 1 Department of Technology in Engineering and Environmental Protection, Bialystok University of Technology, \\ Wiejska St. 45A, 15-351 Białystok, Poland, e-mail: p.wojtowicz@doktoranci.pb.edu.pl
}

Received: 2017.05.15

Accepted: 2017.06.01

Published: 2017.07.01

\begin{abstract}
Discharges from wastewater treatment are among the key sources of pollution, if norms included in the applied legal acts are exceeded. In determining the impact of these objects on water environment it is often assumed that complete mixing wastewater with surface water is in the point or close to the discharge. In fact, the complete mixing of waste water in a short distance from the discharge occurs incidentally depending on the type of sewage receiver. The size and type of specific sewage receiver determines the conditions of self-purification. Complete mixing zone has a huge impact on the intensity of self-purification processes. Therefore, the possibility to determine the size zone of complete mixing of the waste water from the water receiver is important. The issue involves a series of methods, the most computational, which more or less allows to evaluate the distance of mixing waste water. advection, turbulent and molecular diffusion affect mixing wastewater with surface waters. The article discusses the factors influencing the mixing process and the impact of mixing on the self-purification surface waters. The aim of the article is a review of several methods for determining the distance of the segment mix completely discharged wastewater, with regard to the location of their discharge.
\end{abstract}

Keywords: distance of complete mixing, surface waters, wastewater discharge

\section{INSTRODUCTION}

When determining the impact of a sewage treatment plant on particular elements of an aqueous environment, it is often improperly assumed that the receiver waters are mixed with purified sewage at the point of discharge or not far from that site. The route of total mixing of pollutants with receiver waters may be several hundred times longer than the width of the riverbed. In fact, the total mixing of wastewater with receiver waters does not always occur at a short distance from the discharge. Determining the distance, at which full mixing should be considered in a given river cross-section in vertical and transverse dimensions [Rutherford, 1994, Miakoto, 2005]. Determining the distribution of pollutants within the mixing zone is essential to understand the impact of purified wastewater on aquatic or- ganisms, fish migration, and the health of people using the surface water. Due to this, it is also possible to simulate changes in the quality of river water and to obtain information on the possibility of discharging the purified sewage to surface waters. When forecasting changes in surface water quality, it is very important to learn the concentration distribution within the mixing zone because a large area of excessive concentration of harmful and hazardous components can be found within it. This would result in a reduction in water intake for utility purposes and disturbance of habitats responsible for biodiversity conservation [Adamski, 2000, Ostroumov, 2004, Miakoto, 2005].

Mixing of wastewater with receiver waters is possible due to the advection and turbulent and molecular diffusion. The result of these processes is balancing the concentrations of wastewater constituents in the whole volume of water [Ru- 
therford, 1994, Bielski and Gońka, 2001]. The rate and intensity of the mixing processes occurring in the surface waters is influenced by many factors. The distance of the total mixing of wastewater with receiver waters is variable and depends on current water parameters of the receiver - temperature, insolation, dissolved oxygen content, acidity, and presence of toxic compounds [Jarosiewicz, 2007, Dymaczewski, 2011].

Wastewater enters the receiver and its waters are gradually transformed by self-purification processes. According to Mańczak [Mańczak, 1972], self-purification is the biochemical transformation of organic compounds into simpler, inorganic compounds with the involvement of microorganisms, at the expense of water and oxygen. Starmach et al. [Starmach et al., 1976] describe this phenomenon as the sum of processes that bring back the contaminated water to an availability state. This is not a unified process, but composed of many successive, primarily biological and biochemical reactions, due to which, on a certain stretch of the river, pollution is gradually eliminated at varying rates. Physical processes (adsorption, sedimentation, dilution, transport of pollutants into the gas phase), chemical processes (redox reactions, precipitation) and biological processes (assimilation of contamination by microorganisms, organic matter mineralization with a participation of microorganisms) are the most important ones for the pollutants reaching the flowing surface water along with wastewater. These processes condition the self-purification in surface waters. The dynamics of self-purification depends on the amount of impurities introduced, their type, river size, flow velocity, meteorological conditions (light access, temperature, precipitation), substrate composition and conditions of mixing wastewater with receiver waters. For that reason, determine the intensity and the ability to self-renewal of water is very difficult [Jarosiewicz, 2007].

On the basis of research on the process of self-purification of the waters of the Juma River in China, it was found that the process of mixing the receiver waters with purified sewage is mainly dependent on the volume and velocity of river flow, the organic matter of bottom sediment and the occurrence of aquatic vegetation [Krzemińska, 2006, Tian et al., 2011]. What is also important is the river structure - its shape, depth and width of the riverbed, the occurrence of meanders, islands and sandbanks. The location of sewage discharge point from the treatment plant in the cross-section of the river, composition of water and sewage, as well as interactions between all the factors shaping the process of mixing water with the purified sewage, are also important [Rutherford, 1994, Krzemińska, 2006, Żukowski, 2011]. Regulated rivers, as compared to natural streams, are characterized by higher flow rates, which limits sedimentation of the suspensions, reduces the number of plant species and microorganisms living in the aquatic environment [Krzemińska, 2006, Hachoł and Krzemińska, 2008]. As a consequence, the dynamics of self-purification processes in regulated rivers may be limited. Krzemińska et al. [Krzemińska, 2006] determined varying distance of the mixing zone in freely flowing and regulated rivers, indicating the important role of the riverbed regulation in shaping processes occurring in the aquatic environment.

The aim of the article is a review of several methods for determining the distance of the segment mix completely discharged wastewater with regard to the location of their discharge.

\section{REVIEW OF CALCULATION METODS}

The use of computational methods provides information on the way the pollutants are spread within the aquatic environment. The obtained results can be used to determine the retention time of contaminants in the measurement and control section and finally to determine the distance of the wastewater discharge point from the crosssection of its total mixing with receiver waters [Bielski, 2012]. According to Skowysz [Skowysz, 2011], the mixing process should be considered complete when the degree of mixing in the cross-section is at least $98 \%$. In the case of vertical transport of wastewater within receiver waters, the concentration variations of the component at the bottom or the water surface shall be determined. In determining the degree of mixing in the horizontal direction should be pointed to changes the concentration of the component along the river. The designation of a mixing zone for wastewater with receiver waters should not be limited to the distance but also the width. The distance, which the complete mixing occurs is conditioned by factors such as the shape of the river (occurrence of meanders, islands and sandbanks), presence of vegetation on floodplains and in the riverbed, formation and structure of the bottom, 
i.e. the dead zones. The dimensions of the riverbed are also influenced by the depth, width, flow rate of the receiver water, as well as the type and location of the sewage outlet. Tiered approach is helpful in determining the location, size, designation and subsequent control of water mixing zones with purified wastewater. The method consists of five successive stages [Identyfikacja substancji..., 2014] presented in Table 1.

The size of the mixing zone is determined on the basis of a one-dimensional model, which assumed that the concentration of pollutants changed only along the course of the river with equal mixing of pollutants in the transverse profile of the riverbed. Empirical formulae are used to determine the transport of pollutants within aquatic environment, which, based on the hydrometric data, the distance of the wastewater discharge point from the cross-section of its total mixing can be determined [Rutherford, 1994]. It is possible to present a general form of the formula $\left(L_{X}\right)$ used to determine the distance of the mixing path of the wastewater with receiver waters:

$$
\mathrm{L}_{\mathrm{x}}=\alpha_{\mathrm{x}} \cdot \frac{\mathrm{V}_{\mathrm{p}} \cdot \mathrm{s}^{2}}{\mathrm{D}_{\mathrm{y}}}
$$

where: $L_{X}-$ distance of the discharge point from the cross-section of the total cross-sectional mixing $[\mathrm{m}]$,

$\alpha_{X} \quad-\quad$ experimentally determined coefficient,

$V_{p}$ - average flow rate of water in crosssection of the watercourse $\left[\mathrm{m} \cdot \mathrm{s}^{-1}\right]$, $s$ - linear transverse scale, for regulated rivers to be adopted $s \approx 0.7 \mathrm{~b}$; for symmetrical channels $-s \approx 0.5 \mathrm{~b}$, where: $\mathrm{b}$ - width of the water surface $[\mathrm{m}]$,

$D_{y}-$ transverse dispersion coefficient $\left[\mathrm{m}^{2} \cdot \mathrm{s}^{-1}\right]$.

The mixing taking into account the distribution of flow rate and average concentration of pollutants in cross-section, is determined by means of the longitudinal dispersion [Skowysz, 2011], whose coefficient $\left(D_{y}\right)$ can be calculated as follows:

$$
\mathrm{D}_{\mathrm{y}}=\beta_{1} \cdot \mathrm{h} \cdot \mathrm{v}_{*}
$$

where: $\beta_{1}$-coefficient dependent on the riverbed regularity, $\beta_{1}=0.4$ (for rivers with meanders and isles), $\beta_{1}=0.6$ (for regulated riverbeds),

$h$ - average depth of the watercourse [m], $V_{*}$ - dynamic flow rate $\left[\mathrm{m} \cdot \mathrm{s}^{-1}\right]$.

Distance of the mixing path in the vertical direction $\left(L_{y}\right)$ can be calculated using the formula:

$$
\mathrm{L}_{\mathrm{y}}=\alpha_{\mathrm{y}} \cdot \frac{\mathrm{V}_{\mathrm{p}} \cdot \mathrm{s}^{2}}{\mathrm{D}_{\mathrm{z}}}
$$

where: $L_{y}$ - distance of wastewater discharge point from the cross-section of total mixing in vertical direction [m],

$\alpha_{y}-$ experimentally determined coefficient,

$s$ - linear vertical scale $[\mathrm{m}]$,

$D_{z}-$ vertical dispersion coefficient $\left[\mathrm{m}^{2} \cdot \mathrm{s}^{-1}\right]$.

Vertical dispersion coefficient $\left(D_{z}\right)$ should be calculated from the formula:

$$
\mathrm{D}_{\mathrm{z}}=\beta_{2} \cdot \mathrm{h} \cdot \mathrm{v}_{*}
$$

where: $\beta_{2}$ - coefficient (according to Rutherford

$$
\left.-\beta_{2}=0.07\right) \text {. }
$$

Calculation methods presented in Table 2 (Fisher [Adamski, 2000], Sawicki [Sawicki, 2007], Rutherford [Rutherford, 1994], Jirka et al. [Jirka et al., 2005], Rup [Rup, 2006]) are supported by various empirical formulas, however, they differ from one another.

The maximum distance of the full mixing during horizontal mixing can be obtained from the calculations using Rutherford's formula [Ruther-

Table 1. Stages of identification of mixing zones using a tiered approach [Identyfikacja substancji..., 2014]

\begin{tabular}{|c|l|}
\hline $\begin{array}{c}\text { Stages of determining } \\
\text { the mixing zones }\end{array}$ & \multicolumn{1}{|c|}{ Detailed description of the stage } \\
\hline Level 0 & $\begin{array}{l}\text { Identification of contaminants occurrence - identification of potential sources of contamination } \\
\text { and/or analysis of the composition of wastewater discharged into the receiver }\end{array}$ \\
\hline Level 1 & $\begin{array}{l}\text { Preliminary study - selection of sewage discharge points the most strongly affecting the aquatic } \\
\text { environment, elimination of minor points }\end{array}$ \\
\hline Level 2 & $\begin{array}{l}\text { Simple approximation of the mixing zone - estimation of the mixing zone size (e.g. Fischer's } \\
\text { equation, CORMIX1, Visual Plumes2) }\end{array}$ \\
\hline Level 3 & $\begin{array}{l}\text { Detailed assessment of the mixing zone size - application of complex modelling methods, e.g. } \\
\text { Fluid Dynamics Analysis (CFD) models }\end{array}$ \\
\hline Level 4 & Investigation study (optional) \\
\hline
\end{tabular}


Table 2. Empirical formulas used to calculate the distance of the full mixing path of sewage with surface waters [Skowysz, 2011]

\begin{tabular}{|c|c|c|c|}
\hline Author of the formula & \multicolumn{2}{|c|}{ Formula } & Notes \\
\hline \multicolumn{4}{|c|}{ Mixing in the horizontal direction } \\
\hline & \multicolumn{2}{|c|}{ Wastewater discharge point located } & \\
\hline & in the watercourse axis & $\begin{array}{c}\text { on the bank of the } \\
\text { watercourse }\end{array}$ & \\
\hline $\begin{array}{c}\text { Fisher, } 1976 \text { [Adamski, } \\
\text { 2000] }\end{array}$ & $\mathrm{L}_{\mathrm{x}}=0,03 \cdot \frac{\mathrm{V}_{\mathrm{p}} \cdot \mathrm{s}^{2}}{\mathrm{D}_{\mathrm{y}}}$ & $L_{x}=0,12 \cdot \frac{v_{p} \cdot s^{2}}{D_{y}}(a)$ & $\begin{array}{l}\text { Derived by transforming the formula } \\
\text { for the wastewater discharge in the } \\
\text { watercourse axis (a) }\end{array}$ \\
\hline $\begin{array}{c}\text { Sawicki, } 2007 \text { [Sawicki, } \\
\text { 2007] Rutherford, 1994 } \\
\text { [Rutherford, 1994] }\end{array}$ & $\mathrm{L}_{\mathrm{x}}=0,134 \cdot \frac{\mathrm{V}_{\mathrm{p}} \cdot \mathrm{s}^{2}}{\mathrm{D}_{\mathrm{y}}}$ & $\mathrm{L}_{\mathrm{x}}=0,536 \cdot \frac{\mathrm{V}_{\mathrm{p}} \cdot \mathrm{s}^{2}}{\mathrm{D}_{\mathrm{y}}}$ & ${ }^{2}$ \\
\hline $\begin{array}{c}\text { Jirka et al., } 2005 \text { [Jirka } \\
\text { et al., 2005] }\end{array}$ & $\mathrm{L}_{\mathrm{x}}=0,1 \cdot \frac{\mathrm{V}_{\mathrm{p}} \cdot \mathrm{s}^{2}}{\mathrm{D}_{\mathrm{y}}}$ & $\mathrm{L}_{\mathrm{x}}=0,4 \cdot \frac{\mathrm{V}_{\mathrm{p}} \cdot \mathrm{s}^{2}}{\mathrm{D}_{\mathrm{y}}}$ & - \\
\hline Rup, 2006 [Rup, 2006] & $\mathrm{L}_{\mathrm{x}}=0,0725 \cdot \frac{\mathrm{v}_{\mathrm{p}} \cdot \mathrm{s}^{2}}{\mathrm{D}_{\mathrm{y}}}(\mathrm{a})$ & $\mathrm{L}_{\mathrm{x}}=0,29 \cdot \frac{\mathrm{v}_{\mathrm{p}} \cdot \mathrm{s}^{2}}{\mathrm{D}_{\mathrm{y}}}(\mathrm{b})$ & $\begin{array}{l}\text { Derived by transforming the formula } \\
\text { for wastewater discharge on the bank } \\
\text { of the watercourse (a), for } \alpha_{x}=0,6 \text {; s } \\
=0,7 b(b)\end{array}$ \\
\hline \multicolumn{4}{|c|}{ Mixing in the vertical direction } \\
\hline & \multicolumn{2}{|c|}{ Wastewater discharge point located } & \\
\hline & $\begin{array}{l}\text { in the mid-depth of the } \\
\text { watercourse }\end{array}$ & $\begin{array}{l}\text { at the bottom or on the water } \\
\text { surface }\end{array}$ & \\
\hline $\begin{array}{l}\text { Fisher, } 1967 \text { [Adamski, } \\
\text { 2000] }\end{array}$ & $L_{y}=0,03 \cdot \frac{v_{p} \cdot h^{2}}{D_{z}}(a)$ & $L_{y}=0,12 \cdot \frac{v_{p} \cdot h^{2}}{D_{z}}(b)$ & $\begin{array}{l}\text { Derived from the formula for mixing in } \\
\text { the horizontal direction (a), (b) }\end{array}$ \\
\hline $\begin{array}{l}\text { Sawicki, } 2007 \text { [Sawicki, } \\
\text { 2007] Rutherford, 1994 } \\
\text { [Rutherford, 1994] }\end{array}$ & $L_{y}=0,134 \cdot \frac{v_{p} \cdot h^{2}}{D_{z}}$ & $L_{y}=0,536 \cdot \frac{v_{p} \cdot h^{2}}{D_{z}}$ & - \\
\hline $\begin{array}{c}\text { Jirka et al., } 2005 \text { [Jirka et } \\
\text { al., 2005] }\end{array}$ & $\mathrm{L}_{\mathrm{y}}=0,1 \cdot \frac{\mathrm{v}_{\mathrm{p}} \cdot \mathrm{h}^{2}}{\mathrm{D}_{\mathrm{z}}}(\mathrm{a})$ & $\mathrm{L}_{\mathrm{y}}=0,4 \cdot \frac{\mathrm{v}_{\mathrm{p}} \cdot \mathrm{h}^{2}}{\mathrm{D}_{\mathrm{z}}}$ & $\begin{array}{l}\text { Derived by transforming the formula } \\
\text { for wastewater discharge point } \\
\text { located at the bottom or on the free } \\
\text { water surface (a) }\end{array}$ \\
\hline Rup, 2006 [Rup, 2006] & $L_{y}=0,0725 \cdot \frac{V_{p} \cdot h^{2}}{D_{z}}(a)$ & $L_{y}=0,29 \cdot \frac{v_{p} \cdot h^{2}}{D_{z}}(b)$ & $\begin{array}{l}\text { Derived from the formula for mixing in } \\
\text { the horizontal direction (a), (b) }\end{array}$ \\
\hline
\end{tabular}

ford, 1994] and Sawicki [Sawicki, 2007]. In this case, the discharge of wastewater is located on the edge of the watercourse. The shortest distance of full mixing in horizontal mixing can be calculated on the basis of Fisher's formula [Adamski, 2000] assuming the location of wastewater discharge point in the watercourse axis. Distance of the full mixing during horizontal mixing calculated by the method of Rutherford [Rutherford, 1994] and Sawicki [Sawicki, 2007] is almost eighteen times longer than distance of that obtained from the Fisher method [Adamski, 2000]. Taking into account the computational methods assuming the location of wastewater discharge in the watercourse axis, the shortest distance of complete mixing can be obtained according to Fisher's method [Adamski, 2000], while the longest according to a method by Rutherford [Rutherford, 1994] and Sawicki [Sawicki, 2007]. In this case, there will be a 4.5 -fold difference between the calculation results. In the case of the discharge point located on the bank of the watercourse, calculation made using the Fischer's method [Adamski, 2000] will reach the lowest values, whereas those by Ruther- ford [Rutherford, 1994] and Sawicki [Sawicki, 2007] - the highest. The difference in this comparison will also be about 4.5 times as much as in the case of location of the discharge point in the watercourse axis.

When analysing computational methods for mixing wastewater with receiver waters in the vertical direction, it is possible to see the same variation as for horizontal mixing, but in this case wastewater discharges are located in the middle of the depth of the watercourse or at the bottom. The analogies are the consequence of identical coefficients in formulas from both groups of methods.

The authors (Fisher [Adamski, 2000], Sawicki [Sawicki, 2007], Rutherford [Rutherford, 1994], Jirka et al. [Jirka et al., 2005], Rup [Rup, 2006]) of the analysed methods have shown that mixing of wastewater with receiver waters occurs four times faster when the discharge point is located at half the width or depth of the river, rather than locating the outlet at the bank or bottom of the riverbed [Adamski, 2000, Skowysz, 2011]. The range of the mixing zone of wastewater with river water is most commonly determined us- 
ing the Fisher formula [Operat wodnoprawny..., 2012, Identyfikacja substancji..., 2014].

When determining the size of mixing zones, solutions based on morphological parameters of water objects, e.g. riverbed width, are often used. In many European countries, the mixing zones are determined by the distance and width of rivers, as shown in Table 3.

Most of the calculation methods of the size of the mixing zones proposed by European countries are based on a simple relationship - ten times the width of the river.

According to Skowysz [Skowysz, 2011], the distance of the mixing path calculated for Vistula river in the cross-section Włocławek from the formulas proposed by a variety of European countries (Table 3) were similar to the results given by Fisher [Adamski, 2000], Sawicki [Sawicki, 2007], Rutherford [Rutherford, 1994], Jirka et al. [Jirka et al., 2005] and Rup [Rup, 2006].

It is worth noting that it is not always possible to precisely define a mixing zone. The limiting factor is, among others, the wastewater discharging rate significantly affecting the flow rate of the river; quality of the water above the discharge point not corresponding to the obligatory standards and the presence of organic matter in wastewater [Identyfikacja substancji..., 2014].

Flowing water, which is a receiver of treated domestic and industrial wastewater, has the ability to self-purification [Chelmicki, 2001]. This process is more intense in flowing waters. In standing waters it is less intense, therefore, selfpurification occurring only in flowing waters is taken into account [Dojlido, 1995, Brzychczyk at al., 2015]. Self-purification is a process that reduces or eliminates the effects of introduced treated wastewater into the aqueous ecosystems and its importance increases with the continuous de- terioration of the environmental quality [Ostroumov, 2001, Han et al., 2015]. Mixing the treated wastewater with receiver waters is an important element to self-purification. It involves physical processes (adsorption, sedimentation, volatilization), chemical processes (precipitation, redox reactions) and biological processes (biological mineralization, assimilation), which improve the condition of aquatic ecosystems [Vagnetti et al., 2003, Jarosiewicz, 2007,]. Self-purification is based on the phenomenon of suspensions and suspended particles sedimentation, adsorption and mineralization of organic compounds. These components are then taken and utilised by organisms living in the water. The excess of pollutants in the aquatic ecosystem is a deterrent to surface water self-purification [Bielski, 2011, Brzychczyk at al., 2015].

\section{CALCULATING THE DISTANCE OF MIXING ZONES FOR WASTEWATER WITH RECEIVER WATERS}

Table 4 shows the calculated mixing distances according to the Fisher formula [Adamski, 2000] for horizontal mixing and taking into account the wastewater discharge at the bank of the watercourse and distances determined according to the principle proposed in the European Commission guidelines, based on the application of the tenfold width of the riverbed.

The comparison from Table 4 does not coincide with the results achieved by Skowysz [Skowysz, 2011], who found similarities in the results of calculations based on the methods proposed by Fisher [Adamski, 2000] and the European Commission. Perhaps the size of the rivers has made a difference in the calculations. Skowysz [Skowysz, 2011], to the analyses the Vistula river

Table 3. Types of ways to specify the size the mixing zone [Identyfikacja substancji..., 2014]

\begin{tabular}{|c|c|c|}
\hline \multirow{2}{*}{ Country } & \multicolumn{2}{|c|}{ Division of the ways to specify the size of the mixing zone according to: } \\
\hline & zone distance & zone width \\
\hline Austria & \multirow{2}{*}{10 times the width of the river, not more than $1000 \mathrm{~m}$} & - \\
\hline Netherlands & & Up to $25 \%$ of the wet cross-section \\
\hline Germany & Product of river width $[\mathrm{m}]$ and coefficient of value $1-5$ & $\begin{array}{l}\text { Product of river width }[\mathrm{m}] \text { and coefficient of } \\
\text { value } 0.1-0.5\end{array}$ \\
\hline Slovakia & $\begin{array}{l}\text { For rivers with a width of up to } 100 \mathrm{~m} \text { : } 10 \text { times the } \\
\text { width of the river, not more than } 1000 \mathrm{~m} \text {; } \\
\text { For rivers with a width of more than } 100 \mathrm{~m}: 10 \text { times } \\
\text { the width of the river }\end{array}$ & - \\
\hline Sweden & $\begin{array}{l}\text { For small rivers, canals, and ditches: } 10 \text { times the } \\
\text { width of the watercourse, not more than } 1000 \mathrm{~m} \text {; } \\
0.25 \text { times the width of the watercourse, not more } \\
\text { than } 25 \mathrm{~m}\end{array}$ & $100 \mathrm{~m}$ for large receivers (lakes) \\
\hline
\end{tabular}


Table 4. Results of the calculation of the mixing distance of wastewater with receiver waters

\begin{tabular}{|c|c|c|c|}
\hline River & Cross-section & $\begin{array}{c}\text { Distance of mixing path according } \\
\text { to Fisher formula [Adamski, 2000] } \\
{[\mathrm{m}]}\end{array}$ & $\begin{array}{c}\text { Distance of mixing path according } \\
\text { to EC guidelines } \\
{[\mathrm{m}]}\end{array}$ \\
\hline Supraśl & Gródek & 15 & 50 \\
\hline Supraśl & Michałowo & 10 & 30 \\
\hline Czarna & Czarna Białostocka & 12 & 40 \\
\hline
\end{tabular}

was selected, which is completely different from those analysed in this paper. Due to the multitude of parameters affecting the distance of the mixing process, the issue requires further research and calculations, which will allow to develop a universal method for modelling the mixing distance of wastewater with receiver waters.

\section{CONCUSIONS}

The calculation methods proposed by Fisher [Adamski, 2000], Sawicki [Sawicki, 2007], Rutherford [Rutherford, 1994], Jirka et al. [Jirka et al., 2005], and Rup [Rup, 2006] based on computational designs, differ from each other. The largest range of the vertical and horizontal mixing zone can be reached by performing the calculation using Sawicki [Sawicki, 2007] and Rutherford [Rutherford, 1994] methods, while the smallest - by Fisher's [Adamski, 2000]. Literature studies indicate a similarity in the results of calculations proposed by the group of researchers: Fisher [Adamski, 2000], Sawicki [Sawicki, 2007], Rutherford [Rutherford, 1994], Jirka et al. [Jirka et al., 2005], and Rup [Rup, 2006], as well as numerous European countries. The results from the computations according to the proposed methods, based on empirical models recommend the location of wastewater discharge point in the axis of the watercourse and at half of its depth. The proposed location is advantageous due to the small range of the mixing zone.

The complexity of the processes taking place in the aquatic environment and the multiplicity of factors shaping the mixing of treated wastewater with receiver waters makes that to create a uniform and universal method for determining the distance of mixing zone is difficult and often impossible. Many complex mathematical models with a large number of coefficients and variables are used to determine the mechanisms that shape aquatic ecosystems.

\section{Acknowledgements}

The research was carried out as part of the work No. S/WBiIŚ/3/2014 and financed from the resources for education by The Ministry of Science and Higher Education.

\section{REFERENCES}

1. Adamski W. 2000. Modeling of water purification systems. PWN, Warsaw [in Polish].

2. Bielski A., Gońka A. 2001. Determining the route of mixing pollutants in watercourses. Environmental Protection Archives, 27(1), 19-43 [in Polish].

3. Bielski A. 2011. Modeling transport of pollutants in surface waters. Series of Environmental Engineering, Monograph 393, Cracow [in Polish].

4. Bielski A. 2012. Adequate transport of pollutants in the river with bidirectional diffusion in a plane perpendicular to the flow direction. Environmental Protection, 34(2), 19-24 [in Polish].

5. Brzychczyk B., Famielec S., Malinowski M., Salomon J. 2015. Use of clinoptilolite in the process of self-purification water in small water reservoirs. Problems of Agricultural Engineering, VII-IX, z. 3(89), 71-82 [in Polish].

6. Chełmicki W. 2001. Water. Resources, degradation, protection. PWN, Warsow [in Polish].

7. Dojlido J. 1995. Surface water chemistry. Economy and Environment, Bialystok [in Polish].

8. Dymaczewski Z. 2011. Operator's Guide of sewage treatment plant. LEM, Cracow [in Polish].

9. Identification of priority substances and identification of mixing zones in the pilot river basin - Silnica River. 2014. Medlow [in Polish].

10. Jarosiewicz A. 2007. Self-purification process in river ecosystems. Slupsk Biological Works, tom 4, Academy of Pomerania, Department of Water Ecology, Institute of Biology and Environmental Protection, Slupsk [in Polish].

11. Jirka G.H., Weitbrecht V. 2005. Mixing models for water quality management in rivers: continuous and instrumentaneous pollutant releases. Wa- 
ter quality hazards and dispersion of polutants. Springer, Warsaw.

12. Hachoł J., Krzemińska A. 2008. Impact of regulation of Smortawa River on the course of self-purification processes on the example of oxygen indicators. Infrastructure and Ecology of the countryside, nr 9, PAN, 207-216 [in Polish].

13. Han T., Zhang H., Hu W., Deng J., Li Q., Zhu G. 2015. Research of self-purification capacity of Lake Taihu, Environ. Sci. Pollut. Res., 22, 8201-8215.

14. Jarosiewicz A. 2007. Self-purification process in river ecosystems. Slupsk Biological Works, 4, 27-41 [in Polish].

15. Krzemińska A., Adynkiewicz-Piragas M., Kazimierska R. 2006. Evaluation of the oxygen conditions of the lower section of the Smortawa River as a basis for assessment of water self-purification in accordance with the requirements of the Water Framework Directive. Infrastructure and Ecology of Rural Areas, Nr 4/3/2006, PAN, 67-76 [in Polish].

16. Mańczak H. 1972. Technical basis for water protection against pollution. Wroclaw University of Technology, Wroclaw [in Polish].

17. Miakoto J. 2005. Studies transverse dispersion coefficients in the trough of a small river water plants. Conference Materials "Regional problems of water management and hydrotechnics", Szczecin [in Polish].

18. Water Law Operational - Reconstruction of the bridge over the Gloskowka River in Szkolna Street in Gloskow. 2012. Warsaw [in Polish].

19. Ostroumov S.A. 2001. Biological Effects of Sur- factants on Organisms. MAKS-Press, Moscow.

20. Ostroumov S.A. 2004. The Effect of Synthetic Surfactants on the Hydrobiological Mechanisms of Water Self-Purification. Water Resources, 31(5), 502-510.

21. Rup K. 2006. Processes of transferring pollutants in the natural environment. Scientific and Technical Publishing House, Warsaw [in Polish].

22. Rutherford J.C. 1994. River Mixing. Niva Ecosystems National Institute of Water and Atmospheric Research Hamilton, New Zeland. John Wiley \& Sons, Chichester.

23. Sawicki J.M. 2007. Migration of pollutants. PG, Gdansk [in Polish].

24. Skowysz A. 2011. On the use of empirical formulas for calculating the length of the full path of mixing waste water discharged into rivers and canals. Scientific Review Engineering and Environmental Shaping, 53, 237-246 [in Polish].

25. Starmach K., Wróbel S., Pasternak K. 1976. Hydrobiology. PWN, Warsaw [in Polish].

26. Tian S., Wang Z., Shang H. 2011. Study on the Self-purification of Juma River. Procedia Environmental Sciences, 11, 1328-1333.

27. Vagnetti R., Miana P., Fabris M., Pavoni B. 2003. Self-purification ability of resurgence stream. Chemosphere, 52, 1781-1795.

28. Żukowski M. 2011. Virtual lab for modeling process engineering in Environmental Engineering. Gas, Water and Sanitary Technology, Nr 4, 149-152 [in Polish]. 